\title{
Next-Generation Thermionic Solar Energy Conversion
}

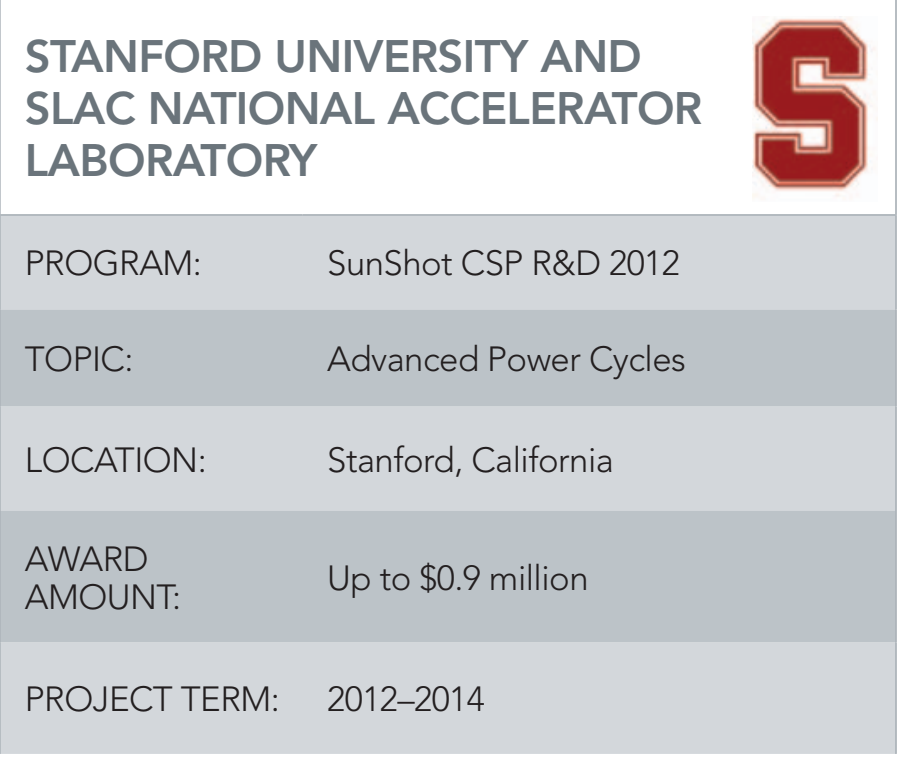

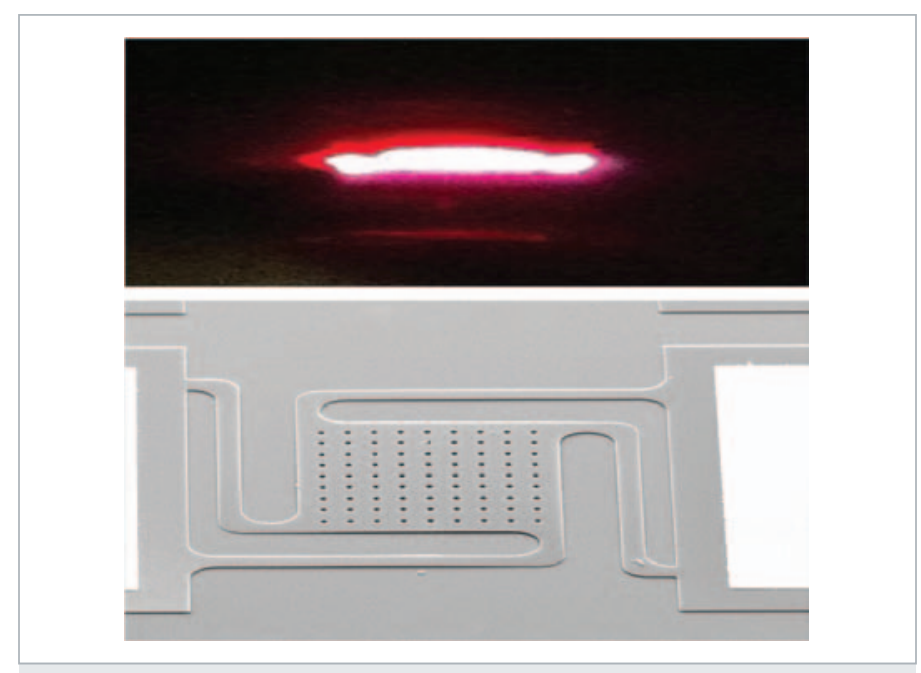

Microscale-enhanced thermionic emitters will enable high-efficiency, solar-to-electrical conversion by taking advantage of both heat and light. Image from Stanford University

\section{CONTACTS}

Project Leader:

Dr. Nicholas Melosh:nmelosh@stanford.edu

\section{MOTIVATION}

The addition of high-temperature topping cycles to conventional concentrating solar power (CSP) electricity generation systems has the potential to significantly increase the efficiency of solar-thermal power stations. Thermionic energy converters are uniquely suited for such topping cycle applications because of their high operating temperatures. To date, this potential remains unrealized because of difficulties with the materials, designs, and manufacturing methods historically used in thermionic energy conversion technology.

\section{PROJECT DESCRIPTION}

This project's objective is to demonstrate the feasibility of photon-enhanced, microfabricated thermionic energy converters as a high-efficiency topping cycle for CSP electricity generation. The research team is using device and system modeling to design and test a next-generation solarthermal energy converter proof-of-concept that is capable of $>15 \%$ thermal-to-electricity efficiency.

\section{IMPACT}

Microscale-enhanced, photon-enhanced thermionic emitters enable high-efficiency solar-to-electrical conversion by taking advantage of high-temperature, solid-state energy production. With the potential to double the electricity output efficiency of solar-thermal power stations, this topping cycle application can significantly reduce the cost of solar-thermal electricity below that of the lowest-cost, fossil-fuel generated electricity.

For more information, visit the project page at: www.solar.energy.gov/sunshot/csp_sunshotrnd_stanford.html. 